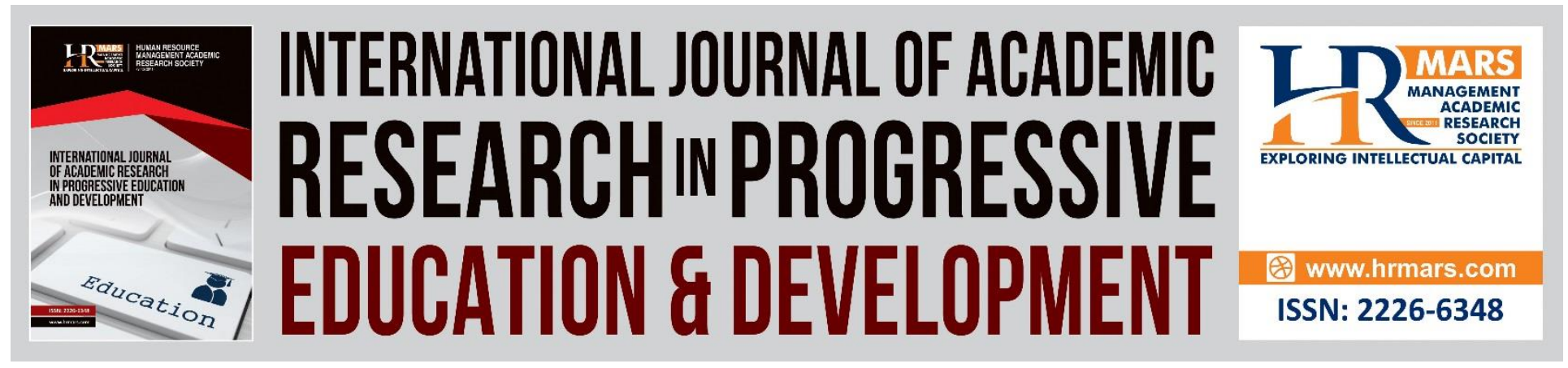

\title{
Specifying Servant Leadership as Reflective-Formative Hierarchical Component Models (HCM) in the Context of PLS-SEM
}

Kamariah Md Salleh, Ahmad Tajuddin Othman, Abdul Ghani Kanesan Abdullah

To Link this Article: http://dx.doi.org/10.6007/IJARPED/v10-i2/9796

DOI:10.6007/IJARPED/v10-i2/9796

Received: 15 March 2021, Revised: 20 April 2021, Accepted: 01 May 2021

Published Online: 18 May 2021

In-Text Citation: (Salleh et al., 2021)

To Cite this Article: Salleh, K. M., Othman, A. T., \& Abdullah, A. G. K. (2021). Specifying Servant Leadership as Reflective-Formative Hierarchical Component Models (HCM) in the Context of PLS-SEM. International Journal of Academic Research in Progressive Education and Development, 10(2), 374-391.

Copyright: (C) 2021 The Author(s)

Published by Human Resource Management Academic Research Society (www.hrmars.com)

This article is published under the Creative Commons Attribution (CC BY 4.0) license. Anyone may reproduce, distribute, translate and create derivative works of this article (for both commercial and non-commercial purposes), subject to full attribution to the original publication and authors. The full terms of this license may be seen

at: http://creativecommons.org/licences/by/4.0/legalcode

Vol. 10(2) 2021, Pg. 374 - 391

http://hrmars.com/index.php/pages/detail/IJARPED

JOURNAL HOMEPAGE

Full Terms \& Conditions of access and use can be found at

http://hrmars.com/index.php/pages/detail/publication-ethics 


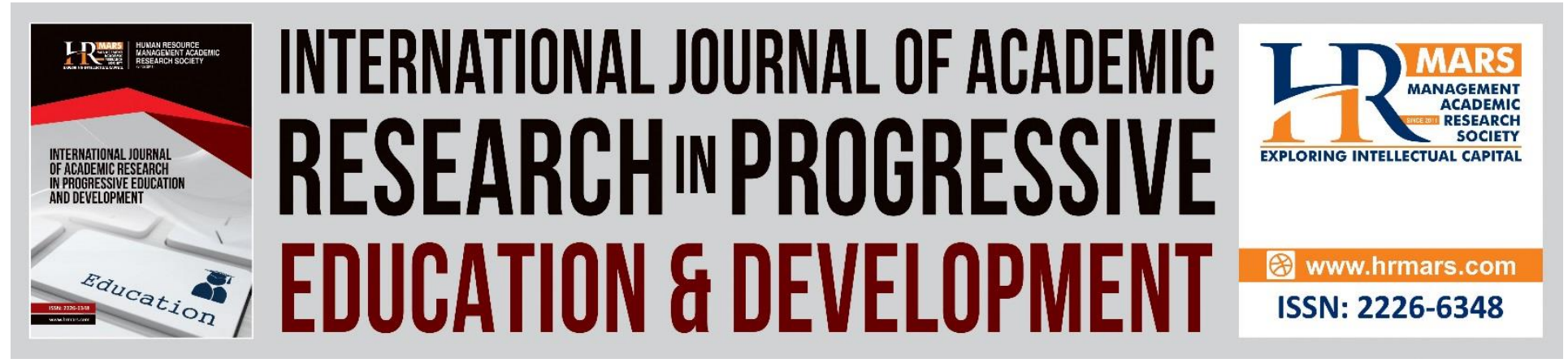

\title{
Specifying Servant Leadership as Reflective- Formative Hierarchical Component Models (HCM) in the Context of PLS-SEM
}

\author{
Kamariah Md Salleh, Ahmad Tajuddin Othman, Abdul Ghani \\ Kanesan Abdullah \\ School of Educational Studies, Universiti Sains Malaysia (USM) \\ Email: kamariah74@student.usm.my
}

\begin{abstract}
Using the Partial Least Squares-Structural Equation Modelling (PLS-SEM) approach, this paper explains the method of validating Servant Leadership (SL) as a reflective-formative construct. Conceptual Skills, Empowerment, Subordinate Growth, Subordinate Prioritization, Ethical Behaviour, Emotional Healing and Creating Value for the community are the seven dimensions of this higher order latent variable. As each Servant Leadership dimension represents a separate concept, these dimensions are therefore not conceptually integrated and do not share a common cause among themselves. Thus, this paper suggests that these dimensions are to be assessed as formative construct to Servant Leadership to fill the methodological gap. In another word, the instrument is measured as a reflective-formative Hierarchical Component Models (HCM). For data analysis purpose, SPSS version 26.0 and Smart-PLS software were used. As this is a result of a pilot study with a rather small sample size, it is recommended to use PLS-SEM as a promising tool, not only for factor analysis but for a complex, hierarchical or higher order model as well. The results of this paper has successfully provided the empirical evidence for Servant Leadership to be considered as the reflective-formative HCM via the assessment of the Measurement Model accordingly. The key implication is that it had highlighted useful guidelines to aid researchers in assessing Servant Leadership as a reflective-formative HCM and the benefits in implementing it. Researchers could report reliable findings about the relationships between the variables of Servant Leadership if they measured the principle of Servant Leadership in the best manner.

Keywords: Servant Leadership, School-based Mentor, Teacher Trainees, Reflective-formative, Hierarchical Component Models, PLS-SEM.
\end{abstract}

\section{Introduction}

Leadership is a substantial mechanism in an organization. There are various theoretical perspectives and leadership styles that have been implemented including contemporary 
leadership styles such as Transformational Leadership and Charismatic Leadership (Mustam and Najam, 2020). Greenleaf (1977), whom founded the term "Servant Leadership" assumed that leaders and their fellow subordinates are a combination that forms an entity (Perna, 2018). Despite a plethora of literatures showing the similarities of other leadership styles to Servant Leadership, van Dierendonck (2011) had succeeded in distinguishing the former to the latter. According to van Dierendonck (2011), the major difference among the other leadership styles was by establishing the different approach in executing the organizational objectives. Majority of the leadership styles utilize the subordinates in order to accomplish the intended goals by alligning them with individual goals. On the contrary, the servant leaders focus primarily on the psychological needs of their subordinates as a priority instead of the organizational missions and visions.

\section{Definition of Servant Leadership}

Servant leadership can be considered as a holistic leadership approach (Eva et al., 2019) that is based on the premise that brings out the best in their subordinates or followers (Liden et al., 2008). Despite the fact that Greenleaf (1977) had never conceptualized the exact definition of Servant Leadership (Liden et al., 2008), he laid a great and extensive foundation, which particularized its significance and theory (Langhof \& Güldenberg, 2019). The servant leader uses the uniqueness and the interests of the subordinates and addresses them accordingly in order to mould and assist them in unleashing their hidden and established potentials by communicating directly and individually (Liden et al., 2008). Therefore, the leaders would be able to understand better on the needs, objectives, capabilities and limitations of their subordinates in order to pursue the betterment of the subordinates. All in all, the accomplishment of the subordinates is a fundamental property of Servant Leadership (Greenleaf, 1977; Liden et al., 2018; Zhang et al., 2021).

This differs from traditional Asian Leadership approaches that has a tendency to have a more elevated level of power distance with the end goal (Madison \& Eva, 2019; Zhang et al., 2021). This study has examined the Servant Leadership of school based mentors utilizing the multidimensional conceptualization by Liden et al. (2008) including emotional healing, creating value for the community, conceptual skills, empowerment, helping subordinates grow and succeed, putting subordinates first and behaving ethically. Past literatures have conducted research using Liden et al. (2008) original measure but did not asses Servant Leadership as reflective-formative Hierarchical Component Models (HCM) (Dapula \& Castano, 2017; Izani Ibrahim \& Yahya Don, 2014; Nolan \& Richards, 2015). Therefore, the main objective of this paper is to test the measure in the context of Partial Least Square Structural Equation Model containing two layer of constructs or in short, reflective-formative HCM to address this methodological gap. The justification of using HCM in assessing the measure is due to a few criterions. First and foremost, it helps to reduce the number of relationships in the Structural Model by providing a simpler model with less variables yet still able to make the PLS path model more parsimonious and easier to understand (Hair et al., 2017). Secondly, HCM tends to solve the problem when there is a trade-off between the variety of information and the thoroughness of the tests to gain more precise details (Sarstedt et al., 2019), if the first order constructs are highly correlated (Hair et 
Vol. 10, No. 2, 2021, E-ISSN: $2226-6348$ @ 2021 HRMARS

al., 2017). Last but certainly not least, by establishing HCMs, researchers are able to provide a platform for minimizing collinearity among formative measures (Sarstedt et al., 2019).

\section{Literature Review}

A number of studies have investigated the impacts of Servant Leadership using Liden et al. (2008) dimensions (Bahari \& Mat, 2017; Brohi et al., 2018; Izani Ibrahim \& Yahya Don, 2014; Krzeminska et al., 2018; Noland \& Richards, 2015) in diverse institution circumstances. However, none of it has been used in the context of school based mentors and teacher trainees. School based mentor has an equally important and significant roles besides the teacher educator in educating and guiding the teacher trainees, especially during the phase of practicum. Moreover, it is essential in preparing future teachers that not only will take part in supporting the belonging and success of all the students, but will also fight for justice and equity (Blair \& Deckman, 2019). Hence, this paper is exploring the advantages of the dimensions of Servant Leadership within the framework of Liden et al. (2008) on the school based mentor from the perspective of teacher trainees during practicum.

\section{Liden et al. (2008) Dimension Theory}

Servant leadership is a form of social support in modern services, including education, as a paradigm shift of leadership (Wu et al., 2020). Greenleaf (1977) defines Servant Leadership as a leader that positions the needs of subordinates above self-interest and provides undivided focus and attention to help subordinates achieve their potential towards optimal career advancement and success in an organization. Servant leadership is also defined as a leadership style that emphasizes individual uniqueness and abilities, given encouragement and support by leaders to attain their full potential, through personal communication involvement with subordinates (Liden et al., 2008).

The ideology is interesting because the Servant Leadership concept focuses around the priority of the servant leaders to serve subordinates as opposed to other conventional leaderships that concentrate on the organization's development, benefit and performance. Greenleaf (1977) founded this leadership philosophy on the premises that an individual in need of service should first provide service that can then lead while serving and then form a community that serves without emphasizing autonomy in the work environment.

Greenleaf (1977) also suggests that the primary purpose of a servant leader is to ensure the wellbeing of his subordinates by helping and inspiring his subordinates to develop self-training and self-improvement in various aspects. Nevertheless, this idea was dismissed as a consequence of fewer specific definitions and vague conceptual operations (Eva et al., 2019; Green et al., 2015).

Spears (1995) provides a clearer and more specific concept by using the Servant Leadership definition in the following ten attributes (Parris \& Peachey, 2013; Powles IV, 2016; Spears, 1995, 2002, 2010; Tischler et al., 2016). The ten key features are (a) listening (b) empathy (c) recovery (d) awareness (e) persuasion (f) conceptualization (g) vision (h) supervision, (i) commitment to 
human development, and (j) community building (Spears, 2002). The concept of Servant leadership is further expanded by Eva et al. (2019) as the (1) distinctive approach-oriented leadership (2) which is manifested via priorities allocated to individual needs and interests and, (3) concern self-orientation towards subordinates in broader organizations and societies. Parris and Peachey (2013) present the conclusion of the Systematic Literature Review that Servant Leadership is a leadership theory that could really help organizations improve the level of subordinate well-being.

The current paper has adopted the dimensions of Servant Leadership proposed by Liden et al. (2008). The seven dimensions have been clarified as below: 2.1.1

(i) Conceptual Skills: Skills that represent the competence of leaders in the fields of organizational awareness and execution of role specification procedures to resolve the difficulties encountered by subordinates and organizations in achieving mission and organizational content (Ibrahim, 2014; Liden et al., 2008). Servant leaders should have broad conceptual understanding to accomplish the mission and vision of people and organisations. Evidently, the ability to formulate insights and to instil an atmosphere of creative and innovative thinking does have a strong connection in optimizing organizational outcomes (Barbuto \& Wheeler, 2006; Spears, 1995)

(ii) Empowerment: Referring to the granting of autonomy to subordinates in problem identification practices and decision-making in problem-solving activities (Liden et al., 2008). Servant leadership acknowledges that there are fundamental qualities of subordinates that include aspects of recognition of individual abilities and privileges (Ibrahim, 2014).

(iii) Subordinates Growth: This component explains the authentic concerns that help to optimize subordinate self-development by providing support, encouragement and guidance (Liden et al., 2008). Servant leaders are adamant that each individual has an ability beyond his or her involvement as workers, and it is the responsibility of the Servant Leaders to explore the added value in unleashing and developing potential from the personal and professional facets of the subordinates in the organization (Barbuto \& Wheeler, 2006).

(iv) Subordinate Prioritization: This dimension concerns the attitude of the servant leader, who verbally communicates and proves the assertion of prioritization of subordinates, especially among subordinates who are directly under his supervision (Liden et al., 2008). Such a mind-set would inspire enthusiasm among subordinates to be more driven in performing the tasks assigned with efficiency and creativity (Ibrahim, 2014).

(v) Ethical Behaviour: Ethics has the sense of how servant representatives deal freely, fairly and genuinely with subordinates (Liden et al., 2008). Leaders who exhibit ethical actions will serve as role models for subordinates while fostering a positive perception of the society and social identity of the organization (Rivkin et al., 2014). 
Vol. 10, No. 2, 2021, E-ISSN: 2226-6348 @ 2021 HRMARS

(vi) Emotional Healing: An action concerning the extent to which a leader is concerned with psychological issues and the well-being of subordinates. This dimension includes an aspect of empathy that is the starting point for an effective listening process (Spears, 1995, 2010). In addition, servant leaders will need to carry out the process of emotional self-recovery before proceeding toward subordinates (Powles IV, 2016). If a servant leader has the ability to rebound and develop strong ties with subordinates, it appears to offer a platform for subordinates to seek advice on professional and personal matters (Barbuto \& Wheeler, 2006). This element of emotional recovery is the same as understanding subordinate issues from more objective third party perspectives (Ibrahim, 2014).

(vii) Creating Value for the Community: the role played by leaders who are mindful and sincere in mobilizing and activating the community in an organization (Liden et al., 2008). The approach used to build a community includes initiatives to foster a sense of collaboration and commitment through effective communication mediums. In addition, collective cooperation will also contribute to resilience in the face of challenges and obstacles (Barbuto \& Wheeler, 2006).

As all these seven dimensions are different from each other, thus, they are better to be developed as the formative indicators for Servant Leadership (the reflective-formative type of higher-order/ HCM construct).

\section{Research Method}

Instrument

The Servant Leadership instrument selected for this study is Servant Leadership Measures (SL28) by Liden et al. (2008). It is comprised of seven dimensions namely Conceptual Skills, Empowerment, Subordinate Growth, Subordinate Prioritization, Ethical Behaviour, Emotional Healing and Creating Value for the community. This study uses the Servant Leadership instrument that has been translated to native language (Malay) by Asnani Bahari and Norsiah Mat (2017). The instrument is a $\mathrm{HCM}$ originating from a combination of reflective-formative construct comprising of 28 items, with four items for each dimension. The instrument details are shown below in Table I.

\section{Table I}

The details of Servant Leadership Measures (SL-28)

\begin{tabular}{lc}
\hline Construct & Item \\
\hline Emotional Healing & $1-4$ \\
\hline Creating Value for the community & $5-8$ \\
\hline Conceptual Skills & $9-12$ \\
Empowerment & $13-16$ \\
Subordinate Growth & $17-20$ \\
Subordinate Prioritization & $21-24$ \\
Ethical Behaviour & $25-28$ \\
\hline
\end{tabular}




\section{Sample Design and Data Collection}

A standard survey was administered, and convenience sampling was utilised to choose the respondents among the teacher trainees in one of the Institute of Teacher Education in North Peninsular Malaysia on the Servant Leadership of their school-based mentor during practicum for the pilot test. As this study will use the second generation statistical analysis technique, namely the PLS Structural Equation Model or the Partial Least Square Structural Equation Modelling (PLS-SEM), the researcher needs to ensure that the essential features for this PLS-SEM analysis are fulfilled. The sample size should be sufficient to produce stable data analysis results. Hair et al. (2017) recommended G*power statistical software to calculate the minimum sample size. Therefore, the $\mathrm{G}^{*}$ Power program was used to ensure that the minimum sample size was attained. The minimum sample size needed for this analysis was 77 respondents, considering the number of predictors in the $G^{*}$ Power program, the results obtained for the $95 \%$ confidence level $(\alpha=.05)$.

A seven-point Likert Scale ranging from 1 (strongly disagree) to 7 (strongly agree) was used to measure responses to the questionnaire's statements for this pilot test. There were 98 respondents comprising 63 Malay and 22 Chinese teacher trainees, whereas the remaining 13 were of mixed ethnicity. Of the sample size, 35 (35.7\%) were males while 63 (64.3\%) were females.

\section{Data Analysis}

As the usage of PLS-SEM is gaining attention among researchers in various disciplines, the focus of the study has becoming more dynamic with the formation of more complex and sophisticated research models. This has led to a proliferation of studies on the utilization of HCM (Sarstedt et al., 2019).

\section{Conceptual Background of HCM}

In general, the HCM or second-order constructs are typically defined by the relationships between the constructs of the model, such as reflective or formative and by the number of levels in the model (Becker et al., 2012). Therefore, the researcher needs to ensure clarification of the Lower Order Component (LOC) measuring items and then evaluate the relationship between LOC and Higher Order Component (HOC) for the HCM variable (Sarstedt et al., 2019). Before specifying the LOC measuring indicators and testing the correlation between LOC and HOC, the nature of the instrument needs to be determined if it is reflective-reflective, reflective-formative, formative-reflective or formative-formative (Cheah et al., 2019). As each Servant Leadership dimension represents a separate concept, these dimensions are therefore not conceptually integrated and do not share a common cause among themselves. Thus, Servant Leadership is classified as a reflective-formative type II second-order construct.

\section{Estimation of HOC in PLS-SEM through Repeated Indicator Approach}

The Repetitive Indicator Approach and the Two-Stage Approach are among the suggested alternatives for estimating latent variable parameters in the HCM model analysis using the PLSSEM study (Ringle et al., 2012; Wetzels et al., 2009). Researchers have opted to use a repeated 
indicator approach in this pilot study measurement model because it is easier to manage and does not result in bias in the measurement model. Furthermore, the key advantage of the repeated indicator approach being capable of estimating all latent variables concurrently instead of estimating the HOC and LOC separately. This avoids interpretational inconsistency and prevents the confounding of interpretation by considering the whole nomological network (Becker et al., 2012).

\section{Assessment of Measurement Model}

Stage 1: Validation approach for evaluating the validity and reliability of the Lower Component Order (LOC) for HCM variables in the measurement model begins by testing the reliability of reflective constructs that correspond to values known as Composite Reliability (CR) in addition to the Cronbach Alpha values. The value of CR is between 0 and 1. Nunally and Bernstein (1994) accept CR values between .60 and .70. Hair et al. (2019) concluded that the minimum value of CR is.70, but that the value of CR is .60 for exploratory research. However, CR values above .95 are feared to reduce construct validity since the extreme value of the item is assumed to be questionable. The recommended minimum value of Cronbach Alpha is .70. Table II reports the CR and Cronbach Alpha values for Servant Leadership. Figure 1 shows the Cronbach Alpha and Outer Loading value for 28 items of all seven constructs and Figure 2 shows the Cronbach Alpha and Outer Loading value for 27 items (after deletion). While Figure 3 shows the CR and Outer Loading value for 28 items of all seven constructs and Figure 4 shows the CR and Outer Loading value for 27 items (after deletion).

\section{Table II}

\begin{tabular}{lcc} 
Cronbach Alpha and CR Values for Reliability & & \\
\hline Construct & Cronbach Alpha & Composite Reliability \\
\hline Servant Leadership & & \\
Emotional Healing & .859 & .905 \\
Creating Value for the community & .917 & .942 \\
Conceptual Skills & .855 & .902 \\
Empowerment & .851 & .909 \\
Subordinate Growth & .830 & .887 \\
Subordinate Prioritization & .889 & .925 \\
Ethical Behaviour & .868 & .910 \\
\hline
\end{tabular}


INTERNATIONAL JOURNAL OF ACADEMIC RESEARCH IN PROGRESSIVE EDUCATION AND DEVELOPMENT

Vol. 10, No. 2, 2021, E-ISSN: 2226-6348 @ 2021 HRMARS

Figure 1

Outer Loading and Cronbach Alpha (28 Items before Removal)

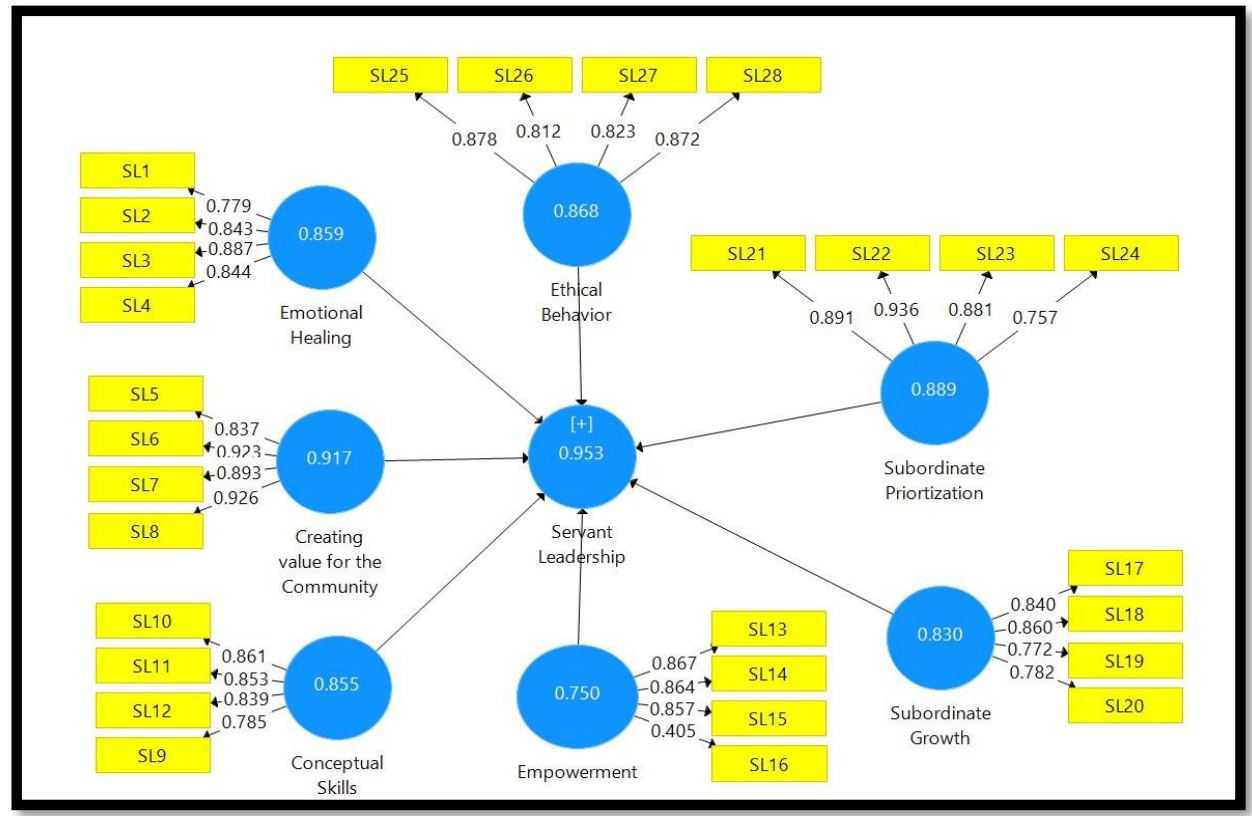

Figure 2

Outer Loading and Cronbach Alpha (27 Items after Removal)

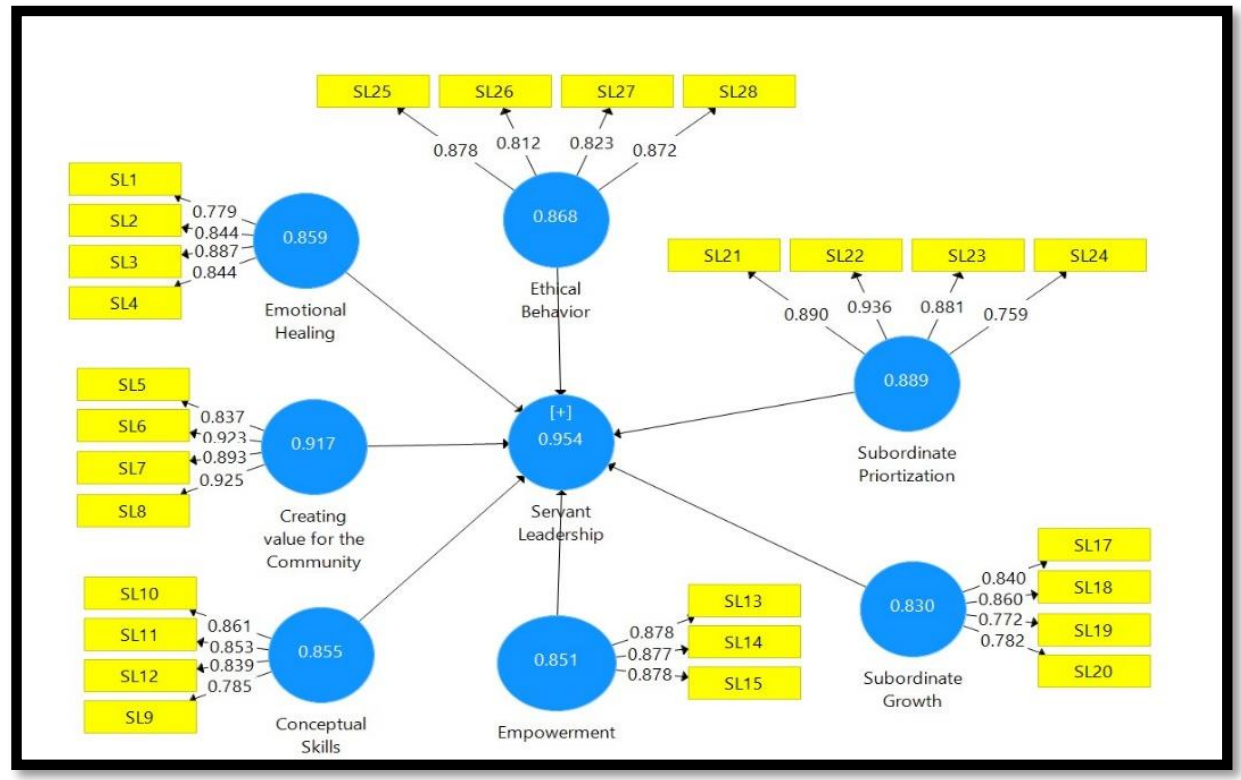


INTERNATIONAL JOURNAL OF ACADEMIC RESEARCH IN PROGRESSIVE EDUCATION AND DEVELOPMENT

Vol. 10, No. 2, 2021, E-ISSN: 2226-6348 @ 2021 HRMARS

Figure 3

Outer Loading and Composite Reliability (28 Items before Removal)

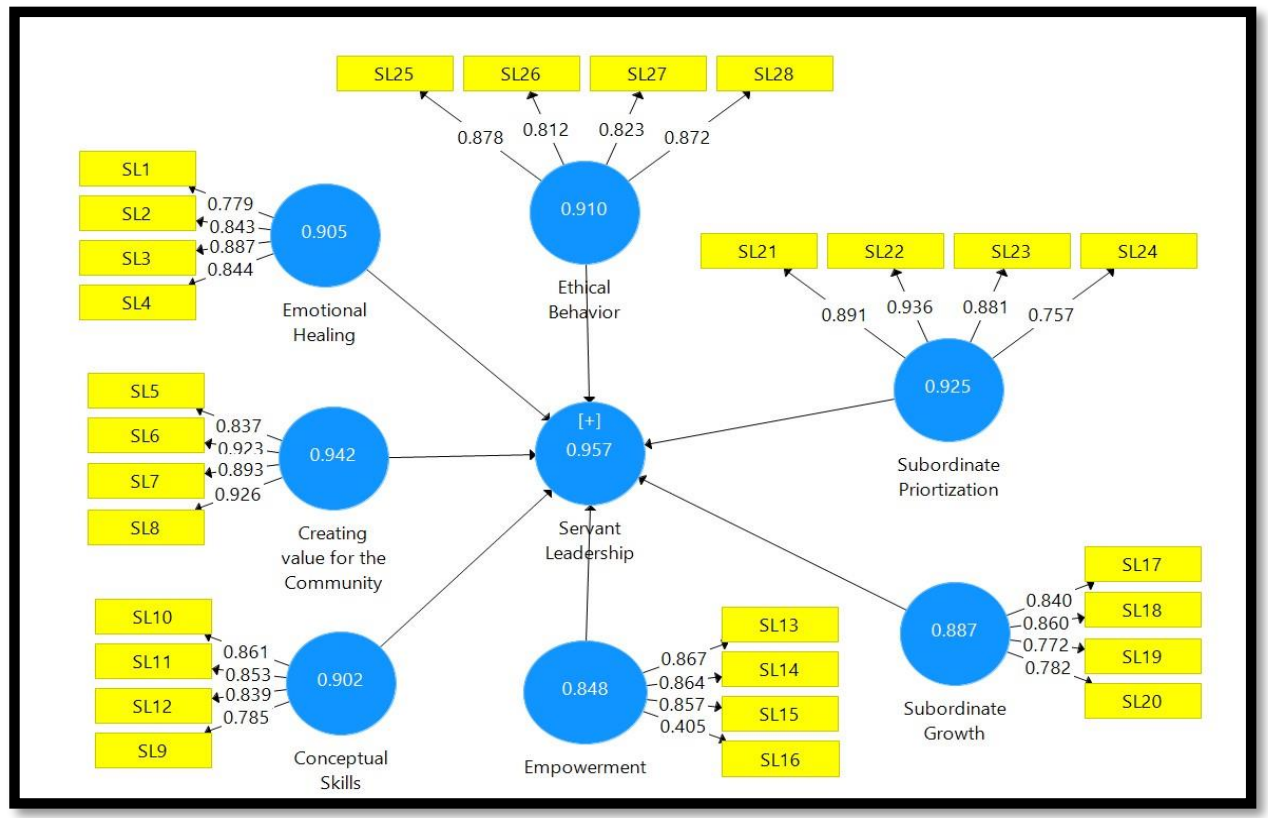

Figure 4

Outer Loading and Composite Reliability (27 Items after Removal)

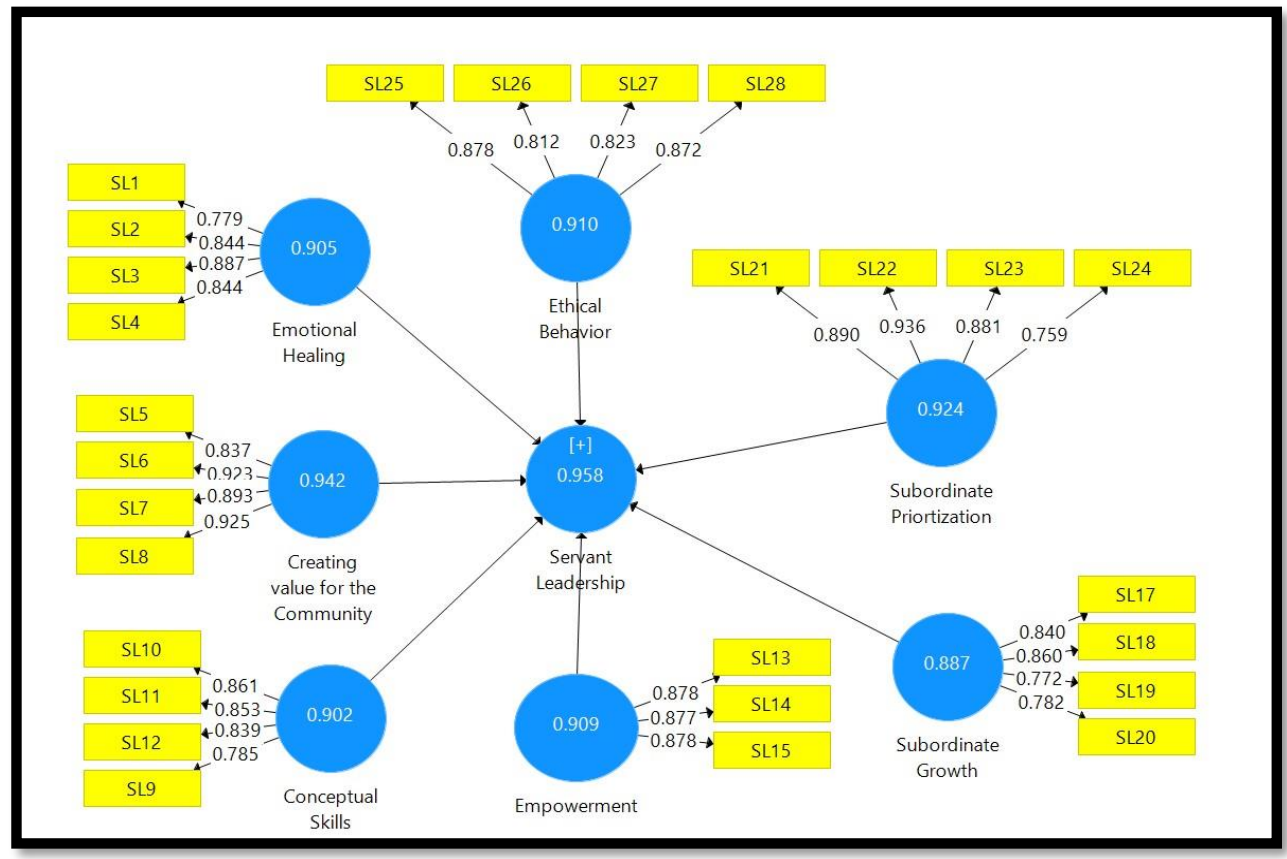


Stage 2: The Convergence Validity Evaluation is conducted to evaluate the extent to which the concepts or constructs are related to each other (Ramayah et al., 2018). Convergent validation measurements for LOCs and reflective measurement models tested the values of Outer Loading $(\mathrm{OL})$ and Average Variance Extracted (AVE). According to Hair et al. (2019), the OL value representing the correlation between the measured item and the proposed construct reaches the value of .708. However, this research will use the methodology of Hair et al. $(2014 ; 2017)$ with the minimum value of .50 for OL and AVE. Nevertheless, indicators with very low outer loading (below .40) should be removed from the construct. The process of obtaining a minimum value of AVE .50 begins by discarding one item or a reflective indicator at a time that has an $\mathrm{OL}$ value of less than .50 consecutively by executing the SmartPLS algorithm calculation process repeatedly after the item has been discarded. Table III shows the OL and AVE values for reflective items and Figure 5 and Figure 6 show the OL and AVE before and after item deletion.

\section{Table III}

Outer Loading (OL) and Average Variance Extracted (AVE) values for reflective items

\begin{tabular}{lcccc}
\hline Variable/Construct & Total Items & $\mathbf{O L}<\mathbf{5 0}$ & Final Total Items & AVE \\
\hline Servant Leadership (SL) & 28 & - & 27 & \\
$\quad$ Emotional Healing & $4 / 28$ & - & 4 & .704 \\
Creating Value for the & $4 / 28$ & - & 4 & .801 \\
community & & & & .697 \\
Conceptual Skills & $4 / 28$ & - & 4 & .770 \\
Empowerment & $4 / 28$ & 1 & 3 & .663 \\
Subordinate Growth & $4 / 28$ & - & 4 & .755 \\
Subordinate Prioritization & $4 / 28$ & - & 4 & .717 \\
Ethical Behaviour & $4 / 28$ & - & 4 & \\
\hline
\end{tabular}


INTERNATIONAL JOURNAL OF ACADEMIC RESEARCH IN PROGRESSIVE EDUCATION AND DEVELOPMENT

Vol. 10, No. 2, 2021, E-ISSN: 2226-6348 @ 2021 HRMARS

\section{Figure 5}

Outer Loading and AVE (Before Item Removal)

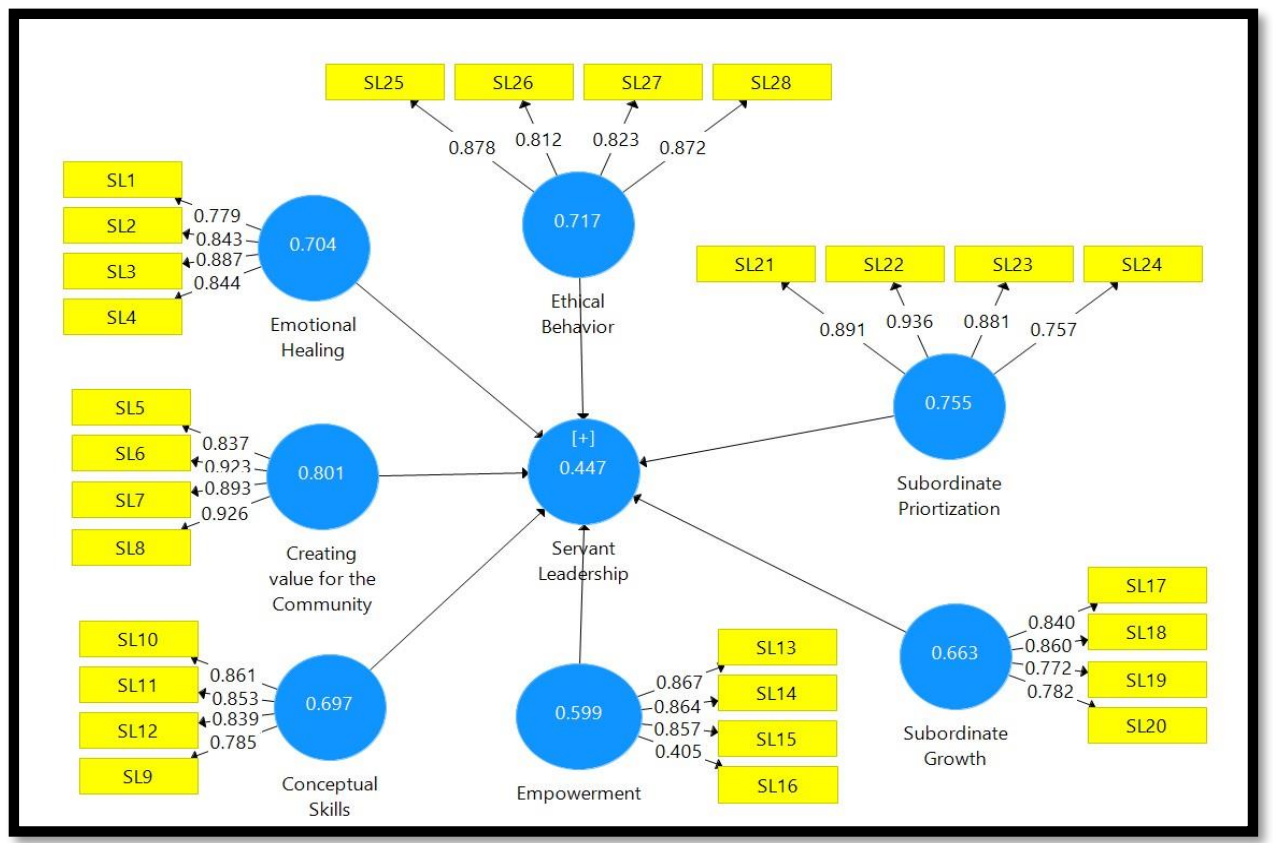

Figure 6

Outer Loading and AVE (After Item Removal)

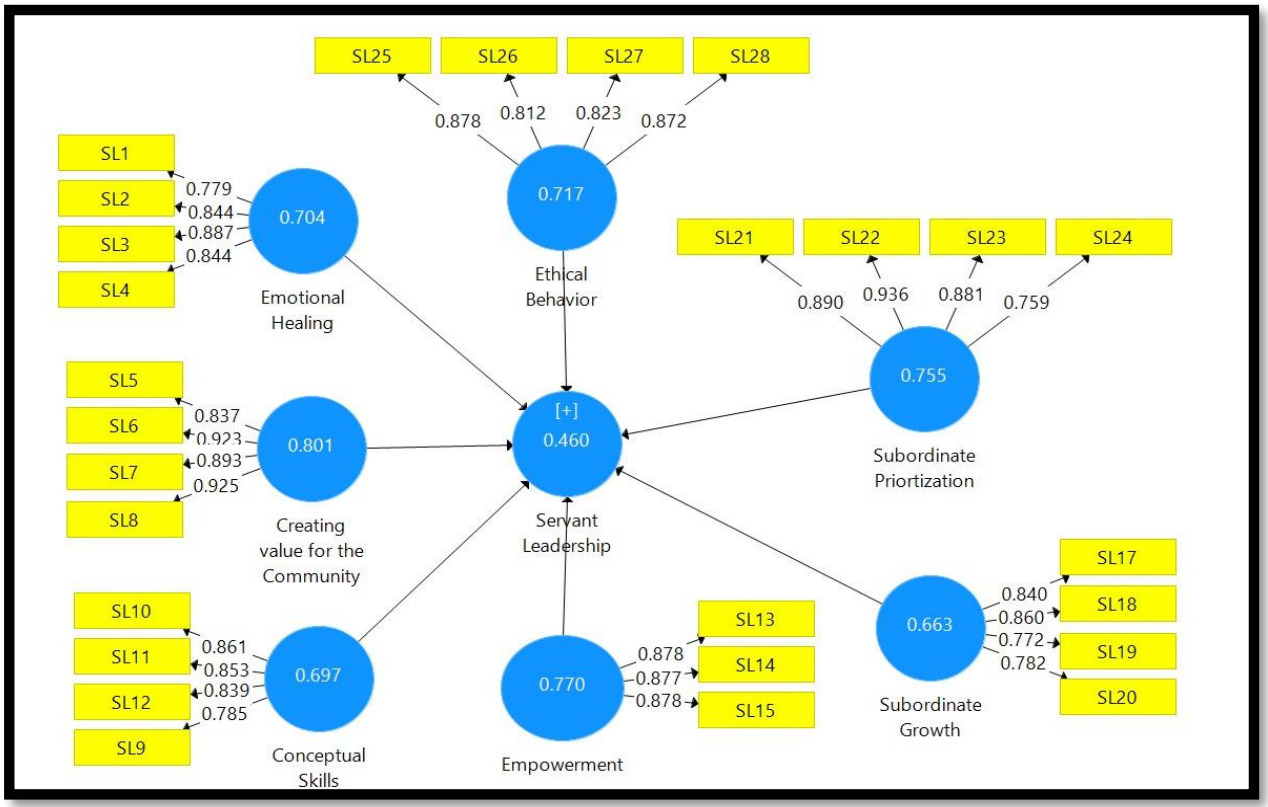

Stage 3: Discriminant Validity Test is performed to ensure that each construct in the model is empirically different (Hair et al., 2019). There are several assessments that can be administered to evaluate discriminatory validity, such as the cross-loading test, the Fornell-Larcker criterion test and the Heterotrait-Monotrait (HTMT) test. The cross-loadings test is typically the first approach to assess the discriminant validity (Hair et al., 2017). It is performed if the 
discrimination validity test is not met. It is implemented by ensuring that the OL value for the specified item is greater than the loading value for other constructs. Dropping items should be done if the loading for other construct is higher than the construct itself.

On the other hand, the Fornell-Larcker test was performed by comparing the square root value of the AVE to the latent value of the correlation. The square root value of the AVE should be greater than the maximum value of any other construct. This is because latent variables need to be better clarified for self-item variance than variance for other latent variables. Table IV reports the results of Fornell-Larcker Criterion Test.

\section{Table IV}

Fornell-Larcker Criterion Test

\begin{tabular}{lccccccc}
\hline & 1 & 2 & 3 & 4 & 5 & 6 & 7 \\
\hline 1. Conceptual Skills & .835 & & & & & & \\
2. Creating Value for the community & .808 & .895 & & & & & \\
3. Emotional Healing & .635 & .646 & .839 & & & & \\
4. Empowerment & .528 & .486 & .422 & .877 & & & \\
5. Ethical Behaviour & .660 & .551 & .458 & .593 & .847 & & \\
6. Subordinate Growth & .702 & .620 & .531 & .416 & .484 & .814 & \\
7. Subordinate Prioritization & .589 & .596 & .469 & .334 & .543 & .668 & .869 \\
\hline
\end{tabular}

Based on Table IV, the AVE power source values for each construct are located in the top and rightmost columns in the respective columns and sections. The value of the AVE power source below it represents the correlation value between the constructs. Specifically, the power source for the AVE of each construct must be greater than the correlation value of the construct with respect to other constructs. Consequently, the value of AVE power source in this pilot study showed a higher value than the correlation value in the column and part of the construct and thus confirmed the Fornell-Larcker criterion test.

Nevertheless, recent studies that critically analysed the efficiency of cross-loadings and the Fornell-Larcker criterion for discriminant validity showed that neither approach reliably identifies discriminant validity issues (Henseler et al., 2015). Therefore, it was suggested that HTMT tests should be administered to determine if there are concerns of discrimination validity in the PLS-SEM analysis. HTMT is defined as the mean value of the item correlation over relative constructs relative to the mean correlation for elements that measure the same construct. High HTMT values provide an indicator of the existence of disinfection validity problems. When the structures in the path model are conceptually more distinct, a lower and thus more moderate threshold value of .85 appears to be appropriate (Henseler et al., 2015). Although Hair et al. (2017) suggest that an HTMT value above .90 indicates a lack of discriminant validity, Henseler et al. (2015) agreed that if the HTMT value is less than 1.00, it shows that the model's reflective constructs vary and that the criteria for discriminant validity for reflective constructs and LOCs have been fulfilled successfully. Consequently, the HTMT can serve as the basis for a statistical discriminant validity test (Hair et al., 2017). 
Vol. 10, No. 2, 2021, E-ISSN: 2226-6348 @ 2021 HRMARS

The following is Table $V$ which reports the value of HTMT with the use of SmartPLS software. All seven constructs reported HTMT values less than 1.00. Henseler et al. (2015) outlined a value of HTMT less than 1.00 proving that the reflective constructs in the model are different and the data reported have proven the conditions for discriminant validity for reflective constructs with the use of Fornell-Larcker and HTMT criterion tests used in this pilot study have been successfully met.

\section{Table V}

Heterotrait-Monotrait Test (HTMT)

\begin{tabular}{lccccccc}
\hline & 1 & 2 & 3 & 4 & 5 & 6 & 7 \\
\hline 1. Conceptual Skills & & & & & & & \\
2. Creating Value for the community & .912 & & & & & \\
3. Emotional Healing & .740 & .724 & & & & & \\
4. Empowerment & .616 & .546 & .493 & & & & \\
5. Ethical Behaviour & .764 & .616 & .531 & .688 & & & \\
6. Subordinate Growth & .830 & .706 & .623 & .495 & .572 & & \\
7. Subordinate Prioritization & .677 & .658 & .536 & .386 & .624 & .778 & \\
\hline
\end{tabular}

Stage 4: The HOC Verification Process, which is a formative construct, involves diligence and accuracy from a technical perspective (Gaskin, et al., 2018) because it needs to address issues such as the number of highly unbalanced indicators in LOC (Becker et al., 2012; Sardstedt et al., 2019). The HOC formative construct validity test was carried out by bootstrapping (5000 resample) by reporting the value of the Beta Coefficient, $t$ statistical value and $p$ value concerning the relationship between LOC and HOC in Table VI.

\section{Table VI}

Validity of Formative Construct (Higher Order Construct)

\begin{tabular}{lccc} 
Construct/Variable & Beta Coefficient & $\boldsymbol{t}$ & $\boldsymbol{p}$ \\
\hline Conceptual Skills -> SL & 0.202 & 14.217 & .001 \\
Creating Value for the community -> SL & 0.222 & 15.548 & .001 \\
Emotional Healing -> SL & 0.170 & 9.473 & .001 \\
Empowerment & 0.124 & 9.974 & .001 \\
Ethical Behaviour -> SL & 0.178 & 1.102 & .001 \\
Subordinate Growth -> SL & 0.172 & 16.971 & .001 \\
Subordinate Prioritization -> SL & 0.185 & 15.993 & .001 \\
\hline
\end{tabular}


Vol. 10, No. 2, 2021, E-ISSN: 2226-6348 @ 2021 HRMARS

\section{Figure 7}

Validity of Formative Construct (Higher Order Construct)

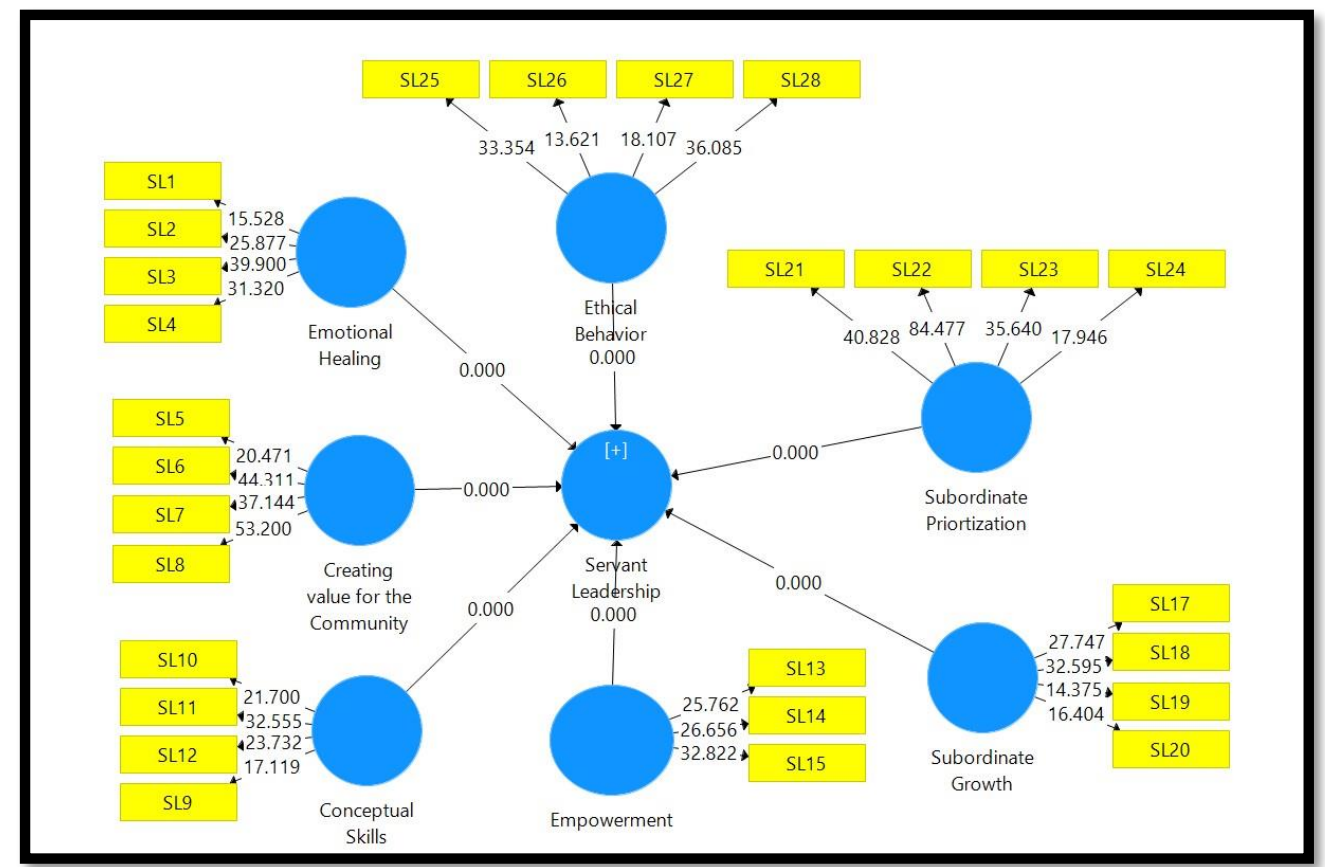

All constructs reported a $p$ value less than .05 , with a statistical value of $t$ exceeding 1.96 and a weighted path with significant values with a Beta Coefficient exceeding 0.1. These findings prove that each LOC construct has a significant relationship with the HOC construct and meets the terms of formative construct validity between the LOC and the HOC.

Sardstedt et al. (2019) also voiced concern over the neglected aspects of collinearity assessment in HCM variables that are reflective-formative in well-known journals, and expressed firmness in the evaluation between LOCs and HOCs in the Measurement Model. Thus, due consideration will be given to the aspect of collinearity by reporting the importance of the Variance Inflation Factor (VIF) in the HOC formative construct. According to Hair et al. (2017) and Ramayah et al. (2018), VIF values not exceeding 5.0 reflect no critical collinearity issues in formative constructs to proceed with testing at the next level, which is the assessment of the Structural Model. Therefore, the Variation Inflation Factor (VIF) value was analysed to investigate the issue of collinearity in the HOC formative construct.

Based on Table VII, the VIF values are in the range from 1.697 to 4.305 . These values indicates no collinearity issues between LOC and HOC formative constructs. Thus, the validity process in the formative construct of the HOC Measurement Model has been implemented. 
Vol. 10, No. 2, 2021, E-ISSN: 2226-6348 @ 2021 HRMARS

\section{Table VII}

Variation Inflation Factor (VIF)

\begin{tabular}{lc}
\hline Variable/Construct & Variation Inflation Factor (VIF) \\
\hline Servant Leadership (SL) & \\
Conceptual Skills & 4.305 \\
Creating Value for the community & 3.350 \\
Emotional Healing & 1.881 \\
Empowerment & 1.697 \\
Ethical Behaviour & 2.276 \\
Subordinate Growth & 2.522 \\
Subordinate Prioritization & 2.199 \\
\hline
\end{tabular}

\section{Contributions, Limitations and Conclusions}

In the Malaysian framework, several studies have revealed the specific dimensions for Servant Leadership. As a result, several related research on the seven dimensions were reviewed as well and all of the Servant Leadership dimensions in this analysis were defined as specific dimensions in the Malaysian context, as previously stated by Izani Ibrahim and Yahya Don (2014), and later confirmed by Asnani Bahari and Norsiah Mat (2017). However, this paper has successfully described Servant Leadership measurement as a reflective-formative measurement model (HCM) with the usage of PLS-SEM analysis. To prevent parameter misspecification, future studies should consider assessing perceived Servant Leadership as a reflective-formative second-order construct. Furthermore, not only it helps to reduce the number of relationships in the Structural Model by providing a simpler model with less variables yet still able to make the PLS path model more parsimonious and easier to understand (Hair et al., 2017), it tends to solve the problem when there is a trade-off between the variety of information and the thoroughness of the tests to gain more precise details (Sarstedt et al., 2019), if the first order constructs are highly correlated (Hair et al., 2017) and researchers are able to provide a platform for minimizing collinearity among formative measures (Sarstedt et al., 2019). Subsequently, researchers will need to formatively decide their construct and select context-specific measurements (Tehseen et al., 2019). It is also recommended to use PLS-SEM to analyse when the sample size is rather small (Hair et al., 2019) as normally done in pilot studies.

There are some limitations in this paper. First, data were obtained using non-probability sampling methods from only one teacher training campus. Therefore, the results could not be generalized on other campuses. Second, the variance in responses over time could not be measured due to the cross sectional design as the data was collected for the pilot study with small sample. However, the key implication is that it had highlighted useful guidelines to aid researchers in assessing Servant Leadership as a reflective-formative HCM and the benefits in implementing it. Researchers could report reliable findings about the relationships between the variables of Servant Leadership if they measured the principle of Servant Leadership in the best manner. 
INTERNATIONAL JOURNAL OF ACADEMIC RESEARCH IN PROGRESSIVE EDUCATION AND

DEVELOPMENT

Vol. 10, No. 2, 2021, E-ISSN: 2226-6348 @ 2021 HRMARS

\section{References}

Bahari, A., \& Mat, N. (2017), "Pengaruh kepimpinan servant ke atas gelagat kewarganegaraan organisasi dalam kalangan guru: satu model konsepsual", Journal of Humanities, Language, Culture and Business, Vol.1 No. 3, pp. 44-54.

Barbuto, J. E., \& Wheeler, D. (2006), "Scale development and construct clarification of servant leadership", Group \& Organization Management, Vol. 31, pp. 300-326.

Becker, J. M., Klein, K., \& Wetzels, M. (2012), "Hierarchical Latent Variable Models in PLS-SEM: Guidelines for Using Reflective-Formative Type Models", Long Range Planning, Vol. 45 No.5-6, pp. 359-394. https://doi.org/10.1016/j.Irp.2012.10.001

Blair, E. E., \& Deckman, S. L. (2019), "We cannot imagine': US preservice teachers' othering of trans and gender creative student experiences", Teaching and Teacher Education, Vol. 86, pp. 1-13. https://doi.org/10.1016/j.tate.2019.102915

Brohi, N. A., Jantan, A. H., Qureshi, M. A., Bin Jaffar, A. R., Bin Ali, J., \& Ab Hamid, K. Bin. (2018), "The impact of servant leadership on employees attitudinal and behavioural outcomes", Cogent Business and Management, Vol. 5. https://doi.org/10.1080/23311975.2018.1542652

Dapula, G. F., \& Castano, M. C. N. (2017). Core self-evaluations, job satisfaction, transformational and servant leadership model in the Roman Catholic education system. Asian Journal of University Education (AJUE), Vol. 13 No. 2, pp.1-14.

Eva, N., Robin, M., Sendjaya, S., van Dierendonck, D. \& Liden, R. C. (2019). "Servant Leadership: A systematic review and call for future research", Leadership Quarterly, Vol. 30 No. 1, pp. 111-132. https://doi.org/10.1016/j.leaqua.2018.07.004

rzeminska, A., Lim, J., \& Härtel, C. E. J. (2018), "Psychological capital and occupational stress in emergency services teams: Empowering effects of servant leadership and workgroup emotional climate", Research on Emotion in Organizations, Vol. 14, pp. 189-215. https://doi.org/10.1108/S1746-979120180000014017

Langhof, J. G., \& Güldenberg, S. (2019), "Servant Leadership: A systematic literature reviewtoward a model of antecedents and outcomes", German Journal of Human Resource Management, pp. 1-37. https://doi.org/10.1177/2397002219869903

Liden, R. C., Wayne, S. J., Zhao, H., \& Henderson, D. (2008), "Servant leadership: Development of a multidimensional measure and multi-level assessment", Leadership Quarterly, Vol. 19 No. 2, pp. 161-177. https://doi.org/10.1016/j.leaqua.2008.01.006

Mustam, N., \& Najam, U. (2020). "Servant Leadership: A bibliometric Review", International Journal of Organizational Leadership, pp. 138-155. https://doi.org/10.33844/ijol.2020.60501

Noland, A., \& Richards, K. (2015). "Servant Teaching: An Exploration of Teacher Servant Leadership on Student Outcomes", Journal of the Scholarship of Teaching and Learning, Vol. 15 No. 6, pp. 16-38. https://doi.org/10.14434/josotl.v15i6.13928

Perna, B. S. (2018), Exploring Organizational and Professional Commitment, Servant Leadership , Occupational Stress, and Humor Perspectives: How Nurses Manage. Dissertations. 1522. https://aquila.usm.edu/dissertations/1522

Sarstedt, M., Hair, J. F., Cheah, J. H., Becker, J. M., \& Ringle, C. M. (2019), "How to specify, estimate, and validate higher-order constructs in PLS-SEM", Australasian Marketing 
Journal, Vol. 27 No. 3, pp. 197-211. https://doi.org/10.1016/j.ausmj.2019.05.003

Tehseen, S., Qureshi, Z. H., Johara, F., \& Thurasamy, R. (2019), "Assessing perceived business success as a reflective-formative (Type II) second-order construct using PLS-SEM approach", Journal of Sustainability Science and Management, Vol. 14 N0. 5, pp. 84-114.

Wu, H., Qiu, S., Dooley, L. M., \& Congying, M. (2020), "The relationship between challenge and hindrance stressors and emotional exhaustion: The moderating role of perceived servant leadership", International Journal of Environmental Research and Public Health, Vol. 17 No. 1. https://doi.org/10.3390/ijerph17010282

Zhang, Y., Zheng, Y., Zhang, L., Xu, S., Liu, X., \& Chen, W. (2021), "A meta-analytic review of the consequences of servant leadership: The moderating roles of cultural factors", Asia Pacific Journal of Management, Vol. 38 No. 1, pp. 371-400. https://doi.org/10.1007/s10490-0189639-z 